\title{
OPIOID PAINKILLERS' DEPENDENCE IN A SAMPLE OF ELDERLY MEDICAL INPATIENTS
}

\section{Opioid dependence in an elderly sample}

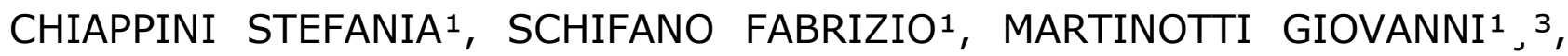
STRASSER JOHANNA CRISTINA ${ }^{4}$, BONNET UDO ${ }^{2,4}$, SCHERBAUM NORBERT2

1 Psychopharmacology, Drug Misuse and Novel Psychoactive Substances Research Unit, School of Life and Medical Sciences, University of Hertfordshire, Hatfield, AL10 9AB, Herts, UK.

2 Department of Addictive Behaviour and Addiction Medicine, LVR-Klinikum Essen, Hospital of the University of Duisburg-Essen, Germany.

3 Department of Neurosciences, Imaging and Clinical Sciences, Università degli Studi G. D’Annunzio, Chieti-Pescara, Italy.

4 Department of Psychiatry, Psychotherapy and Psychosomatic Medicine, Evangelisches Krankenhaus Castrop-Rauxel, Academic Teaching Hospital of the University of Duisburg-Essen, D-44577 Castrop-Rauxel, Germany.

\section{Corresponding author:}

Professor Fabrizio Schifano

f.schifano@herts.ac.uk 


\begin{abstract}
BACKGROUND: Over the past few years there has been a growing concern towards prescription opioid misuse/dependence in the elderly. Thus, our study aimed at investigating the prevalence of previous and current prescribing opioid dependence among elderly medical inpatients recruited from a large German Hospital.

METHODS: This cross-sectional study analysed a cohort of inpatients aged 65 years and older who were assessed with the help of a structured clinical interview (SCID-I). Levels of past/current opioid; benzodiazepines; hypnotics; and non-opioid analgesics' dependence were assessed.

RESULTS: Out of a total of 2,108 elderly inpatients admitted to the hospital over 6 months, some 400 fulfilled the inclusion criteria and agreed to participate to the survey. Some $43(10.8 \%)$ subjects presented with a dependence on opioid analgesics; in 41 cases this was a current, and for 22 $(51.2 \%)$ a de novo, condition. Addiction severity was considered mild and severe respectively in $65.1 \%$ and $11.6 \%$ of cases, with tilidine and oxycodone having been the most typically reported molecules.

CONCLUSIONS: Further research is warranted, to better understand possible risk factors of prescription drug misuse/abuse/addiction in this vulnerable population. Clinicians should be updated and informed regarding both prescription medication misuse potential and safe prescribing practices in the elderly.
\end{abstract}

KEY WORDS: opioid dependence, elderly, drug abuse, addiction 


\section{Introduction}

Compared with younger adults ${ }^{1-5}$ opioid use, misuse and dependence are considered relatively rare phenomena among the elderly (age 65 and older). Although very little related information is available ${ }^{6-7}$, over the last few years there has been a growing concern regarding opioid medication/painkillers' misuse in the elderly ${ }^{8-10}$. Age and age-related features may increase the complexity of opioid risks, including overdose and deaths, contributing to the global public health burden of the opioid epidemic ${ }^{7-11}$.

\section{Growing prescription levels of opioid analgesics}

A growing availability of prescription opioid analgesics has been registered worldwide ${ }^{6 ; 11-12}$, with this trend including all formulations of opioid analgesics except for injectables ${ }^{11}$. In the United States (US) opioid analgesic sales, measured in morphine milligram equivalents (MMEs), have gradually increased year after year from 1992 to 2017, with oxycodone, hydrocodone, and fentanyl being the most popular molecules ${ }^{11}$. Similarly, the total consumption of opioids in Europe has increased steadily ${ }^{13}$. In France, in the 2004-2017 timeframe, the annual prevalence of opioid use has increased significantly, especially with respect to oxycodone $(+1,950 \%)$, codeine $(+150 \%)$, and tramadol $(+123 \%)$. Also, both 'opioid shopping/pharming' and opioid-related hospitalizations and deaths have increased ${ }^{14}$. In the United Kingdom (UK), over the past two decades a marked and progressive rise in prescribing of opioid painkillers has emerged $^{15}$. Compared to the US, possibly due to both a more regulated healthcare system and a European more conservative approach to pain management ${ }^{16}$, smaller levels of opioid epidemic have been recorded.

Trends in opioid painkillers' misuse in the elderly

Despite the elderly high levels of prescription opioids' use, and the risks associated with long-term intake ${ }^{17-19}$, due to the lack of empirical research the overall prevalence of prescription drug abuse among the elderly is difficult to estimate. However, an increase in opioid-related deaths in the US involving all age groups, including the elderly (from $2.0 \%$ in 2000 to $3.5 \%$ in 2017), has been recorded ${ }^{20}$. Furthermore, it has been suggested that the non-medical use of prescription opioids among all adults aged $>$ or $=50$ years is likely to increase ${ }^{9-10 ; 21-22}$. In fact, a 'baby boom' cohort of consumers, who have used large levels of psychoactive drugs, has been aging into older adulthood $5 ; 9 ; 21 ; 23-$ 24 , increasing the number of older adults with a substance use disorder $(S U D)^{25}$. This cohort may arguably shift from illicit26 to prescription drugs, including opioids and benzodiazepines $23 ; 27$.

Compared with younger adults, the elderly differ for cognitive aspects, biological factors, psychological characteristics, and social issues ${ }^{9}$. This complex clinical scenario makes it difficult to assess SUDs in this age range ${ }^{2}$, with screening instruments to diagnose drug abuse in the elderly not being available ${ }^{22}$. Chronic pain, joint replacement surgery, and malignancies are all associated with a long-term prescription opioid treatment, and this may facilitate the occurrence of a condition of drug dependence ${ }^{6-7 ; 10 ; 17 ; 21-22 ; 27-29}$, further contributing to the elderly cognitive impairment ${ }^{29-30}$. Factors associated with the transition to a chronic use of opioids after initiation in opioid-naïve 
elderly adults may include: low-income; female gender; poor physical and mental conditions; chronic pain; THC misuse ${ }^{5-6}$; and prescription of remaining pain/sleep/psychiatric medications ${ }^{31}$. Similar to what occurs in younger adults $5 ; 32$, older adults may obtain opioid analgesics whilst taking advantage of physicians' prescriptions $(47.7 \%)$; friends/relatives $(23.2 \%)$; and fake prescriptions (5.3\%).

Considering the above gaps in knowledge, we aimed here at investigating the prevalence of previous and current prescribing opioid dependence among elderly medical inpatients recruited from a large German Hospital.

\section{Methods}

Data collection

This is a cross-sectional study conducted from April 17 to October 17, 2013, at the Evangelisches Krankenhaus Castrop-Rauxel Hospital, Germany. Survey data were collected as described by Cossmann et al. ${ }^{2}$ Indeed, data were here collected using a structured face-to-face interview, based on an operationalized diagnostic classification system, of elderly patients (e.g. 65 years and older) with a focus on substance addiction. In brief, the sample included here patients from all medical departments (except for the intensive care unit), who were treated for at least four days and who agreed to be engaged in a formal clinical interview. Addictive disorders were identified using Section E (Abuse and Dependence on Psychotropic Substances) of the Structured Clinical Interview (SCID-I), an interview guide following the criteria of the Diagnostic and Statistical Manual of Mental disorders, 4th edition (DSM-IV-TR) ${ }^{33}$. The interview identified the 12-month current and past prevalence rates of any dependence. Physical dependence was characterized by tolerance and/or withdrawal symptoms; whilst psychological dependence included: ingestion of opioids' larger amounts, or over a longer period, than intended; and/or a persistent desire or unsuccessful efforts to cut down or control opioid use ${ }^{33}$. Those with a score of less than 25 points at the Mini-Mental State-MMSE test and/or with an inadequate control of the German language were excluded. According to the SCID-I results, a mild dependence was characterized by the presence of 3 dependence symptoms, accompanied by a minor impairment in occupational performances and social relationship activities. Conversely, a severe dependence included more than 6 symptoms together with profound impairment of occupational performances and social relationship skills and activities. A moderate dependence presented with an intermediate symptomatology between mild and severe ${ }^{2}$. Patients were requested to report on the use of opioid analgesics, including codeine, morphine, oxycodone, hydromorphone, hydrocodone, tramadol, tilidine, (racemic-)methadone, levomethadone, and tapentadol. Also, benzodiazepines and Z-drugs (zaleplon, zolpidem, and zopiclone) and non-opioid analgesics, such as acetaminophen, metamizole, flupirtine, and nonsteroidal anti-inflammatory drugs (NSAID) were here taken into consideration as well at the interview.

\section{Ethics}


The study was approved on March 5, 2013, by both the Medical Association Westfalen-Lippe and the Medical Department of Westfälische Wilhelms University of Munster Ethics Committees.

\section{Statistical Analyses}

Results are here provided as absolute and relative frequencies. A correlation analysis was performed using two-sided $X^{2}$ tests (significance level: .05).

\section{Results}

During the period of data collection, out of a total of 2,108 elderly inpatients identified and considered eligible, 447 agreed to take part to the study. Among them, 1 patient did not give his consent to be interviewed; 42 subjects presented with an inadequate MMSE score; and 4 subjects did not possess an adequate command of the German language. Hence, 400 subjects were recruited for the survey. The age spectrum ranged from 65 to 91 years, with an average age of 75.45 years $(S D=6.4)$. Data regarding the elderly sample here considered were collected from the following hospital wards: Surgery ( $n$ $=123,30.5 \%)$, Internal Medicine $(n=94,23.6 \%)$, Neurology $(n=70$, $17.6 \%)$, Geriatrics $(n=54,13.5 \%)$, Psychiatry $(n=28,7 \%)$, Gastroenterology ( $n=25,6.3 \%)$, and Gynaecology $(n=6,1.5 \%)$. For the complete description and distribution of sociodemographic variables in the sample please refer to Cossman et al. 2

Some 43 older adults (43/400: 10.8\%) fulfilled the criteria for dependence on opioid analgesics; in 41 cases this was a current condition, whilst 2 subjects were in sustained full remission. Females were more represented than males ( $F / M$ : $\left.35 / 8=4.375 ; X^{2}=7, p=.008\right)$ and the subjects' average age at opioid dependence onset was 70.53 years $(S D=8.51)$. The mean duration of dependence was 5.84 years $(S D=6.29)$; the dependence level was typically reported as mild (28/43 patients: $65.1 \%$ ), whilst in a minority of cases this was considered a severe condition (5/43: $11.6 \%)$. Most reported substances were here tilidine and oxycodone, having been reported in 17 and 14 patients, respectively (Table 1 ).

For 8 patients $(8 / 43: 18.6 \%)$, a dependence condition relating to more than one opioid was reported. Interestingly, for almost half of the sample $(n=22$, $51.2 \%$ ) the opioid dependence at onset was reported as a de novo (e.g. without previous or concurrent addiction to other substances) condition (Table 2 ). Most typical de novo cases involved female subjects (19/22: 86.4\%); prescribed with tilidine or oxycodone; reporting a mild severity of the condition $(18 / 22$ : $81.8 \%)$; and frequently including physical symptoms (21/22: $95.45 \%)$. Together with opioid dependence, a nicotine addiction was here identified in $10(23.3 \%)$ subjects, whilst a concurrent dependence on either sedatives (benzodiazepines and Z-drugs) or non-opioid analgesics (e.g. NSAIDs and metamizole) was identified respectively in $8(18.6 \%)$ and $3(7 \%)$ subjects (Table 3 ).

\section{Discussion}

The presented findings showed that prescribing opioids' dependence in the elderly is not an uncommon phenomenon. In fact, to the best of our 
knowledge, unique data relating to the significant levels (e.g. 10.2\%) of prescribing opioids' dependence condition prevalence in a sample of elderly medical inpatients were here provided. Present findings are consistent with the observation that elderly patients are a population at risk with regards to opioid use and misuse ${ }^{17 ; 34}$. In fact, several findings make the elderly more at risk of being prescribed with opioids, including age-related physiological changes; occurrence of frequent medical co-morbidities; and the large prevalence levels of chronic, including both cancer and neurological, pain 6;32;35-37. Although in Germany there is no evidence of a proper opioid epidemic, prescribing rates of opioid analgesics have been growing steadily over the last 25 years $7 ; 32 ; 38$, for treating both malignant and non-malignant pain conditions. Consistent with this, the elderly inpatients here considered were recruited from a vast range of medical and surgical wards. Assessing the prevalence of substance misuse in elderly German psychiatric inpatients who had been admitted over three years, a previous study ${ }^{39}$ found a current substance abuse in 182/941 patients (19.3 $\%)$, but only 8 of them $(4.4 \% ; 0.8 \%$ of the whole study population), fulfilled the ICD-10 criteria for opioid abuse. This difference in rate levels could be explained in considering the arguably large range of medical and surgical conditions affecting the elderly inpatients here considered, hence likely to be representative of a general hospital population.

Females, who present with longer life expectancy levels then males, emerged here as being at particular risk of developing a prescribing opioid dependence condition ${ }^{40-41}$. Although data regarding comorbid mental health illnesses at intake were unfortunately not made here available, one could argue that females may be at higher risk of both developing chronic pain-related medical conditions ${ }^{42-44}$, and psychological distress/depression ${ }^{45}$.

Consistent with previous literature findings $6 ; 39-46$, current data showed a nonnegligeable level of a concurrent dependence condition on hypnotics, tranquilizers and sedatives, e.g. benzodiazepines and Z-drugs. This is a reason of concern, since this pharmacological interaction may be associated with cognitive function decline ${ }^{47}$, psychomotor abnormalities and excessive central nervous system (CNS) depressant side effects ${ }^{3}$, with a dose-dependent risk of falls/hip fractures $3 ; 6 ; 41 ; 48-49$. Furthermore, as advised by the 2015 American Geriatrics Society (AGS) Beers Criteria, potential drug-drug interactions, especially if involving opioids, should be avoided, and prescription of $\geq 3$ CNS agents should be considered as inappropriate prescribing ${ }^{50}$.

Regarding the opioid drugs involved, the synthetic compound tilidine appeared here to be the most reported opioid analgesic. Launched in the early 1970s, tilidine is a prodrug of nortilidine, a $\mu$-opioid receptor agonist, available as a prescription drug and controlled by the German Narcotics Law. In Germany, tilidine is provided as well in combination with naloxone, and this formulation is exempt from some of the provisions of the Narcotic Drugs Act ${ }^{52}$. Apart from a single case, the tilidine cases here reported were relating to the lone molecule combination. Although there is no evidence for its abuse in the elderly population, the tilidine formulations' analysis of prescription patterns has described frequent reports of both high dosage intake and prescription frauds ${ }^{51}$. 
Oxycodone was here the second most reported opioid painkiller. The molecule is considered as one of the commonly abused prescription drugs worldwide, because of both its high levels of prescribing and potency $12 ; 31 ; 42 ; 44 ; 49 ; 52$. Among the 14 oxycodone cases, 12 were reported here as ingesting the oxycodone/naloxone combination which is available in Germany. Risks of opioid use, abuse, and fatal overdoses are reportedly increased if oxycodone is used along with other medications, including not only sedatives, but also muscle relaxants and remaining non opioid painkillers $2 ; 44 ; 52$. To prevent diversion and misuse, oxycodone tablets were recently modified into a controlled-release, tamper-resistant, formulation ${ }^{53-4}$.

\section{Limitations}

The study might present with some limitations, including the survey's limited recruitment rate. On the other hand, elderly hospitalized patients typically present with multiple medical co-morbidities; high levels of ill-health; and partial cognitive function decline issues, with all these factors possibly having significantly impaired the subjects' availability to carry out the survey full psychiatric interview. Because of the characteristics of this vulnerable population, present results should not be generalized to the whole age group. In being a cross-sectional study with a single interview only, no data relating to possible opioids' adverse events following the administration of a specific medication, alone or in combination, were here made available. This issue may however deserve further detailed investigation. Furthermore, data on concurrent diagnoses and possible mental health issues were here not made available, and this may have limited current data interpretation. Again, objective measures such as blood and/or urine screenings were here not considered. However, given that the clients were hospitalized, one could argue that the medication compliance, and the actual opioid ingestion, was here confirmed. Finally, one would argue that the present 'addictive disorders' cases were in fact relating to "pseudo addiction" (e.g. drug-seeking behaviour that simulates true addiction, at times identified in chronic pain patients who are receiving inadequate pain medication levels) phenomena. Conversely, to avoid as much as possible any diagnostic uncertainties, the robust SCID-I clinical assessment, based on solid internationally approved diagnostic criteria (DSMIV-TR ${ }^{33}$ ) was here administered.

In an ageing society, the misuse of prescription opioids among the elderly is an issue of increasing relevance. There is limited published research on this topic, and continued efforts to better measure this public health problem and develop age-specific and culturally appropriate intervention are needed to ensure optimal health outcomes. There is also the need for education among health professionals regarding both prescription medication misuse and safe prescribing practices in the elderly population $6-8 ; 10 ; 12 ; 24 ; 32 ; 36 ; 55$. Indeed, clinicians will need to distinguish 'pseudo addiction' phenomena, associated with drug-seeking behaviour due to poorly managed persistent pain, from those scenarios which are consistent with true prescription opioids' abuse ${ }^{7 ; 9 ; 56-}$ 57. Specific prescription guidelines, including optimal titration procedures; considering measures to assess pain relief levels; estimating the time frame 
for prescribing; and considering alternative medications/therapies should be considered $12 ; 32 ; 58$. Clinicians should avoid multi-drug prescribing practices, especially if this involves CNS depressants $17 ; 32$. Prescribers should be attentive to possible warnings of misuse and risky behaviours involving prescription drugs, such as early refill requests and 'doctor shopping' behaviour, which normally involves visiting multiple doctors with the same health problem, particularly with chronic diseases and multiple comorbidities ${ }^{12 ; 59}$. Finally, drug monitoring programmes, such as both the US PDMP60 and the Florida Brief Intervention and Treatment for Elders (BRITE) ${ }^{55}$ should be made more largely and promptly available worldwide ${ }^{12}$.

\section{Acknowledgements}

The data here presented and commented were collected as part of a larger study, e.g. Cossman JC, Scherbaum N, and Bonnet U. Substance Addiction in Old Age. A Cross-Sectional Study in a German Hospital. GeroPsych. 2016, 29:17-27.

\section{Disclosure}

No potential conflict of interest was reported by the authors. The authors received no funding for this work.

\section{References}

[1] Boscarino JA, Rukstalis M, Hoffman SN, Han J], Erlich PM, Gerhard GS, Stewart WF. Risk factors for drug dependence among out-patients on opioid therapy in a large US health-care system. Addiction 2010; 105(10): 17761782.

[2] Cossmann JC, Scherbaum N, Bonnet U. Substance Addiction in Old Age. A Cross-Sectional Study in a German Hospital. GeroPsych. 2016; 29(1): 17-27.

[3] Naples JG, Gellad WF, Hanlon JT. Managing Pain in Older Adults: The Role of Opioid Analgesics. Clin Geriatr Med. 2016; 32(4): 725-735.

[4] Sale JE, Thielke S, Topolovec-Vranic J. Who is addicted to, and dying from, prescription opioids? J Am Geriatr Soc. 2010; 58(7): 1401-1402.

[5] Schepis TS, Mc Cabe SE, Teter C]. Sources of opioid medications for misuse in older adults: results from a nationally representative survey. Pain 2018; 159(8): 1543-1548.

[6] Maree RD, Marcum ZA, Saghafi E, Weiner DK, Karp JF. A Systematic Review of Opioid and Benzodiazepine Misuse in Older Adults. Am J Geriatr Psychiatry 2016; 24(11): 949-963.

[7] Wolter DK. [Abhängigkeitspotenzial und andere Risiken von Opioidanalgetika im Alter]. Sucht 2017; 63(2): 99-114. 
[8] Carew AC, Comiskey C. Treatment for opioid use and outcomes in older adults: a systematic literature review. Drug Alcohol Depend. 2018; 182:48-57.

[9] Kalapatapu RK, Sullivan MA. Prescription use disorders in older adults. Am ] Addict.2010; 19(6): 515-522.

[10] Schonfeld $L$, King-Kallimanis $B L$, Duchene DM, Etheridge RL, Herrera JR, Barry $\mathrm{KL}$, et al. Screening and brief intervention for substance misuse among older adults: the Florida BRITE project. Am J Public Health 2010; 100(1): 108114.

[11] Food and Drug Administration [FDA] (2018). FDA Analysis of Long-Term Trends in Prescription Opioid Analgesic Products: Quantity, Sales, and Price Trends [cited 2019 Sept 3]. Available from: https://www.fda.gov/media/111695/download.

[12] Steinman MA, Komaiko KD, Fung KZ, Ritchie CS. Use of opioids and other analgesics by older adults in the United States, 1999-2010. Pain Med. $2015 ; 16(2): 319-327$.

[13] Palmaro A, Lapeyre-Mestre M. Trends in opioid analgesics use in Europe: a ten-year perspective. Clin Therap.2015; 37(8): e4.

[14] Chenaf C, Kaboré JL, Delorme J, Pereira B, Mulliez A, Zenut M, Delage N, Ardid D, Eschalier A, Authier N. Prescription opioid analgesic use in France: Trends and impact on morbidity-mortality. Eur J Pain.2019; 23(1): 124-134.

[15] Curtis HJ, Croker R, Walker AJ, Richards GC, Quinlan J, Goldacre B. Opioid prescribing trends and geographical variation in England, 1998-2018: a retrospective database study. Lancet.2019;6(2): 140-150.

[16] Rosenquist R, Van Zundert J. (2018). The Opioid Epidemic: What Can We Learn from Europe? A Q\&A with Pain Management Experts [cited 2019 Sept 3]. Available from: https://consultqd.clevelandclinic.org/the-opioid-epidemicwhat-can-we-learn-from-europe/.

[17] Carter MW, Yang BK, Davenport M, Kabel A. Increasing Rates of Opioid Misuse Among Older Adults Visiting Emergency Departments. Innov Aging 2019; 3(1): igz002.

[18] Substance Abuse and Mental Health Services Administration [SAMHSA]. (2017). National Survey of Drug Use and Health (NSDUH) Releases [cited 2019 Sept 3]. Available from: https://www.samhsa.gov/data/release/2017-nationalsurvey-drug-use-and-health-nsduh-releases.

[19] Solomon DH, Rassen JA, Glynn RJ, Lee J, Levin R, Schneeweiss S. The comparative safety of analgesics in older adults with arthritis. Arch Intern Med. 2010; 13, 170(22): 1968-1976. 
[20] National Institute for Health Care Management [NIHCM] (2018). The Evolution of the Opioid Crisis: 2000-2017. [cited 2019 Sept 3]. Available from: https://www.nihcm.org/categories/the-evolution-of-the-opioid-crisis-20002017.

[21] Culberson JW, Ziska M. Prescription drug misuse/abuse in the elderly. Geriatrics 2008; 1, 63(9): 22-31.

[22] Simoni-Wastila L, Yang HK. Psychoactive drug abuse in older adults. Am J Geriatr Pharmacother. 2006; 4(4): 380-394.

[23] Blow FC, Barry KL. Alcohol and substance misuse in older adults. Curr Psychiatry Rep.2012; 14(4): 310-319.

[24] Gfroerer J, Penne M, Pemberton M, Folsom R. Substance abuse treatment need among older adults in 2020: the impact of the aging baby-boom cohort. Drug Alcohol Depend.2003; 1;69(2): 127-135.

[25] Wu LT, Blazer DG. Illicit and nonmedical drug use among older adults: a review. J Aging Health.2011; 23(3): 481-504.

[26] Arndt S, Clayton R, Schultz SK. Trends in substance abuse treatment 1998-2008: increasing older adult first-time admissions for illicit drugs. Am J Geriatr Psychiatry 2011; 19(8): 704-711.

[27] Wu LT, Blazer DG. Substance use disorders and psychiatric comorbidity in mid and later life: a review. Int J Epidemiol.2014, 43(2): 304-217.

[28] Chang YP. Factors associated with prescription opioid misuse in adults aged 50 or older. Nurs Outlook.2018, 66(2): 112-120.

[29] Oh G, Abner EL, Fardo DW, Freeman PR, Moga DC. Patterns and predictors of chronic opioid use in older adults: A retrospective cohort study. PLOS ONE 2019, 14(1): e0210341.

[30] Lalic S, Gisev N, Bell JS, Korhonen MJ, Ilomaki J. Predictors of persistent prescription opioid analgesic use among people without cancer in Australia. $\mathrm{Br}$ J Clin Pharmacol.2018, 84(6): 1267-1278.

[31] Musich S, Wang SS, Slindee L, Kraemer S, Yeh CS. Characteristics associated with transition from opioid initiation to chronic opioid use among opioid-naive older adults. Ger Nurs.2019, 40: 190-196.

[32] Preuss CV, Kalava A, King KC. Prescription of Controlled Substances: Benefits and Risks (2019). Source StatPearls [Internet]. Treasure Island (FL): StatPearls Publishing. 
[33] American Psychiatric Association [APA] (2000). Diagnostic and Statistical Manual of Mental Disorders (4th ed., text rev.). Washington, DC.

[34] Henderson AW, Babu KM, Merchant RC, Beaudoin FL. Prescription Opioid Use and Misuse Among Older Adult Rhode Island Hospital Emergency Department Patients. R I Med J.2013; 98(3): 28-31.

[35] Cochran G, Rosen D, McCarthy RM, Engel RJ. Risk Factors for Symptoms of Prescription Opioid Misuse: Do Older Adults Differ from Younger Adult Patients? J Gerontol Soc Work 2017; 60(6-7): 443-457.

[36] Nicholson B. Responsible prescribing of opioids for the management of chronic pain. Drugs 2003; 63(1): 17-32.

[37] West NA, Dart RC. Prescription opioid exposures and adverse outcomes among older adults. Pharmacoepidemiol Drug Saf. 2016; 25:, 539-544.

[38] Schubert I, Ihle P, Sabatowski R. Increase in Opiate Prescription in Germany Between 2000 and 2010. A Study Based on Insurance Data. Dtsch Arztebl Int. 2013; 110(4): 45-51.

[39] Wetterling T, Junghanns K. Substance Abuse in Older Psychiatric Inpatients. Sucht. 2017, 63 (2): 115-121.

[40] Musich S, Wang SS, Slindee LB, Saphire L, Wicker E. Characteristics of New-Onset and Chronic Sleep Medication Users Among Older Adults: A Retrospective Study of a US Medigap Plan Population using Propensity Score Matching. Drugs Aging 2018; 35(5): 467-476.

[41] Han B, Gfroerer JC, Colliver JD, Penne MA. Substance use disorder among older adults in the United States in 2020. Addiction 2009; 104(1): 88-96.

[42] Bedene A, Lijfering WM, Niesters M, van Velzen M, Rosendaal FR, Bouvy $M$, et al. Opioid Prescription Patterns and Risk Factors Associated With Opioid Use in the Netherlands. JAMA Netw Open 2019; 2; 2(8): e1910223.

[43] García-Esquinas E, Rodríguez-Sánchez I, Ortolá R, Lopez-García E, Caballero FF, Rodríguez-Mañas L, Banegas JR, et al. Gender Differences in Pain Risk in Old Age: Magnitude and Contributors. Mayo Clin Proc. 2019; Sep;94(9): 1707-1717.

[44] Werber A, Marschall U, L'hoest E, Hauser W, Moradi B, Schiltenwolf M. Opioid Therapy in the Treatment of Chronic Pain Conditions in Germany. Pain Physician 2015; 18: E323-E331.

[45] Scherbaum N, Bonnet U. [Neurobiology of opioid dependence]. Schmerz 2018; 32(6): 483-494. 
[46] Rhee TG. Coprescribing of Benzodiazepines and Opioids in Older Adults: Rates, Correlates, and National Trends. J Gerontol A Biol Sci Med Sci. 2018, Dec 17.

[47] Billioti de Gage S, Pariente A, Bégaud B. Is there really a link between benzodiazepine use and the risk of dementia? Exp Opin Drug Saf. 2015; 14: 733-747.

[48] Buckeridge D, Huang A, Hanley J, Kelome A, Reidel K, Verma A, et al. Risk of injury associated with opioid use in older adults. J Am Geriatr Soc. 2010; 58(9): 1664-1670.

[49] Han B, Sherman SE, Palamar J]. Prescription opioid misuse among middle-aged and older adults in the United States, 2015-2016. Prev Med. 2019; 121: 94-98.

[50] American Geriatrics Society [AGS]. American Geriatrics Society 2015 Beers Criteria Update Expert Panel (2015). American Geriatrics Society 2015 Updated Beers Criteria for Potentially Inappropriate Medication Use in Older Adults [cited 2019 Sept 3]. Available from: https://www.sigot.org/allegato docs/1057 Beers-Criteria.pdf.

[51] Radbruch L, Glaeske G, Grond S, Münchberg F, Scherbaum N, Storz E, et al. Topical review on the abuse and misuse potential of tramadol and tilidine in Germany. Subst Abus.2013; 34(3): 313-320.

[52] West NA, Severtson SG, Green JL, Dart RC. Trends in abuse and misuse of prescription opioids among older adults. Drug Alcohol Dep. 2015; 149: 117121.

[53] Larance B, Dobbins $T$, Peacock A, Ali R, Bruno R, Lintzeris N, et al. The effect of a potentially tamper-resistant oxycodone formulation on opioid use and harm: main findings of the National Opioid Medications Abuse Deterrence (NOMAD) study. Lancet Psychiatry 2018; 5(2): 155-166.

[54] Severtson SG, Ellis MS, Kurtz SP, Rosenblum A, Cicero TJ, Parrino MW, et al. Sustained reduction of diversion and abuse after introduction of an abuse deterrent formulation of extended release oxycodone. Drug Alcohol Depend. 2016; 168: 219-229.

[55] Schonfeld L, Hazlett RW, Hedgecock DK, Duchene DM, Burns LV, Gum AM. Screening, Brief Intervention, and Referral to Treatment for Older Adults With Substance Misuse. Am J Public Health 2015; 105(1): 205-211.

[56] Bonnet $U$, Richter $E L$, Isbruch $K$, Scherbaum N. On the addictive power of gabapentinoids: a mini-review. Psychiatr Danub. 2018; 30(2): 142-149. 
[57] Huang AR, Mallet L. Prescribing opioids in older people. Maturitas 2013; 74: $123-129$.

[58] Dowell D, Haegerich TM, Chou R. CDC Guideline for Prescribing Opioids for Chronic Pain. MMWR Recomm Rep. 2016; 65(1): 1-49.

[59] Biernikiewicz M, Taieb V, Toumi M. Characteristics of doctor-shoppers: a systematic literature review. J Mark Access Health Policy. 2019;7(1):1595953. doi: $10.1080 / 20016689.2019 .1595953$.

[60] Haffajee RL. Prescription Drug Monitoring Programs - Friend or Folly in Addressing the Opioid-Overdose Crisis? N Engl J Med. 2019; 381: 8. 
TABLE 1. Opioid analgesics' dependence in elderly medical inpatients

\begin{tabular}{|c|c|}
\hline & $\begin{array}{c}\text { Opioid analgesics' dependence } \\
\text { Total cases }=43(100 \%)\end{array}$ \\
\hline \multicolumn{2}{|l|}{ Gender: } \\
\hline $\mathrm{F}$ & 35 (81.3\%) \\
\hline M & 8 (18.6\%) \\
\hline Mean age (yy) & 75.45 (range:65-91, SD=6.4) \\
\hline Mean age (yy) at opioid dependence onset & $70.53(S D=8.51)$ \\
\hline Mean duration of dependence (yy) & 5.84 years $(S D=6.29)$ \\
\hline Presence of physical addiction symptoms & $40(93.0 \%)$ \\
\hline \multicolumn{2}{|l|}{ Dependence levels: } \\
\hline -mild & $28(65.1 \%)$ \\
\hline -medium & $10(23.3 \%)$ \\
\hline -severe & $5(11.6 \%)$ \\
\hline -Current & 41 (95.3\%) \\
\hline -Sustained remission & $2(4.7 \%)$ \\
\hline \multicolumn{2}{|l|}{ Opioids being involved: } \\
\hline -Buprenorphine & 2 \\
\hline -Fentanyl & 1 \\
\hline -Hydromorphone & 6 \\
\hline -Morphine & 4 \\
\hline -Oxycodone & 14 (12/14: Oxycodone + Naloxone formulation) \\
\hline -Piritramide & 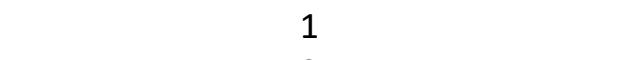 \\
\hline -Tapentadol & 3 \\
\hline -Tilidine & 17 \\
\hline -Tramadol & 3 \\
\hline
\end{tabular}


TABLE 2. Previous and new onset dependence in opioid analgesics addicted older adults

\begin{tabular}{|l|c|}
\hline & $\begin{array}{c}\text { Opioid analgesics addiction in older } \\
\text { adults } \\
\text { Total cases = 43 }\end{array}$ \\
\hline Previous dependence on/abuse of a different substance & $\mathbf{1 4} \mathbf{( 3 0 . 2 \% )}$ \\
Alcohol & 3 \\
Nicotine & 10 \\
Non-Opioid analgesics & 1 \\
Sedatives & 0 \\
\hline Parallel dependence onset on a different substance & $\mathbf{1 1 ( 2 5 . 6 \% )}$ \\
Alcohol & 0 \\
Nicotine & 0 \\
Non-opioid Analgesic & 3 \\
Sedatives & 8 \\
\hline De novo-dependence on Opioid Analgesics & $\mathbf{2 2 ~ ( 5 1 . 2 \% )}$ \\
\hline
\end{tabular}

